\title{
Международное ядерное
}

право

\section{МЕХДУНАРОДНЫЙ КОНТРОЛЬ В МЕЖДУНАРОДНОМ ЯДЕРНОМ ПРАВЕ (К Договору о всеобъемлющем запрещении ядерных испытаний от 10/IX 1996 г).}

\section{P.М. В а л е е в *}

Международное ядерное право является сравнительно новой отраслью современного международного права. В отечественной международно-правовой литературе возникновение данной отрасли рассматривают в связи с возникновением межтосударственньх отношений по использованию атомной энергии. Появление нового источника энергии обусловило его применением как в военньх целях, так и для мирного использования. Потенциальная опасность, которую таит в себе применение ядерного оружия, столь же большая опасность радиоактивного заражения в результате нарушения ядерной технологии в промышленности, судоходстве, в атомных электростанциях и в других объектах, поставила перед государствами неотложный вопрос о конкретном и более полном правовом регулировании международных и внутригосударственных отношений по использованию ядерной энергии. По существу на исходе XX века сложилась группа международно-правовых норм по регулированию отношений государств в связи с появлением принципиального нового источника энергии, открывающего новые перспективы для развития человечества.

Само название данной отрасли первоначально было связано с получением энергии от деления атома, затем научно-технический прогресс позволил получать более мошную энергию в результате осуществления цепных реакций деления тяжелых ядер и реакции термоядерного синтеза легких ядер.

В международно-правовой литературе данную отрасль одни авторы именуют атомным правом, другие ядерным правом'. Если исходить из правового регулирования современных более высоких технологий получения энергии и их использования, то более логичным и справедливым

* Доктор юридических наук, профессор кафедры государственного и международного права юридического факультета КГУ. Подробнее об авторе см. в № 3 нашего журнала за 1997 год. 
было бы назвать данную новую отрасль международным ядерным правом $^{2}$, которое базируется как на основополагающих принципах современного международного права, так и на специальных принципах, возникших вместе с самой отраслью:

- принцип мирного использования ядерной энергии;

- принцип обеспечения ядерной безопасности на Земле, в том числе от радиоактивного заражения;

- принцип обеспечения безопасности развития ядерной энергетики;

- принцип нераспространения ядерного оружия.

В научных исследованиях называются и другие специальные отраслевые принципы ${ }^{3}$.

Нормы международного ядерного права регулируют отношения государств, а также международных организаций в различных сферах их деятельности по использованию ядерной энергии: по защите окружаюшей среды, по использованию космического пространства, мирового океана, эксплуатации морских и речных судов, режима международных и государственных территорий и т. д. По существу нормы международного ядерного права носят комплексный характер. За полвека XX столетия в международном ядерном праве принято и кодифицировано довольно большое количество международно-правовых норм. Данный процесс продолжается и в настоящее время, поскольку в этом есть особая необходимость, что вытекает из разработки современных ядерных технологий и их усовершенствования. Применение ядерной энергии интенсивно развивается как в мирных целях, так и в военно-промышленном комплексе. В связи с этим, важное значение для мирового сообшества приобретает неукоснительное соблюдение имеюшихся международно-правовых норм в данной области. Наряду с соблюдением принципа добросовестного выполнения государствами своих международно-правовых обязательств первостепенную роль в международных соглашениях по ядерному праву отводится международному и национальному контролям.

Прежде чем приступить к анализу контрольного механизма, установленного в международных соглашениях по ядерному праву, попытаемся сгруппировать нормы международного ядерного права по предмету регулируемых ими отношений:

I. В сфере разработки, испытания, размещения ядерного оружия:

a) Договор о запрешении испытаний ядерного оружия в атмосфере, в космическом пространстве и под водой от 5 августа $1963 \mathrm{r}$.

б) Договор о всеобъемлющем запрещении ядерных испытаний от 24 сентября $1996 \mathrm{r}$.

в) Договор о нераспространении ядерного оружия от 1 июля 1968 г.

г) Договор о запрешении размешения на дне морей и океанов и в его недрах ядерного оружия и других видов оружия массового уничтожения от 11 февраля 1971 г.

д) Договор о запрешении ядерного оружия в Латинской Америке от 14 января 1967 г.

е) Договор о безъядерной зоне в южной части Тихого океана от 6 августа 1985 г. и другие соглашения о безъядерных районах, свободных от ядерного оружия. 
В стадии разработки находятся соглашения по ядерному оружию, В том числе Конвенция о запрешении радиологического оружия, Конвенция о запрешении применения ядерного оружия ${ }^{4}$.

II. В сфере радиоактивного заражения планеты:

a) Международная конвенция о предотврашении загрязнения моря сбросами отходов и других материалов - $1972 \mathrm{r}$.

б) Конвенция о физической защите ядерного материала 1980 r.

в) Конвенция об оперативном оповешении о ядерной аварии и о помощи в случае ядерной аварии или радиоактивно аварийной ситуации 1986 г.

г) Базельская конвенция о контроле за трансграничной перевозкой опасных отходов и их удаления от 22 марта 1989 г.

III. Нормы, предусматривающие ответственность за ядерную деятельность и зашиту трудящихся.

a) Конвенция о зашите трудяшихся от ионизируюшей радиации $1960 \mathrm{r}$.

б) Международная конвенция о гражданской ответственности за ядерный ушерб 1963 г.

в) Конвенция об ответственности перед третьей стороной в области ядерной энергии 1960 г.

г) Конвенция об ответственности операторов ядерных судов 1962 г. (не действует).

д) Конвенция о гражданской ответственности в области морских перевозок ядерных материалов 1971 г.

Многие из названных международных соглашений регулируют отношения государств по защите окружающей среды, обеспечивают международную безопасность, защищают права и свободы человека и по существу являются источниками и других отраслей международного права.

Отдельные нормы, относящиеся к международному ядерному прав, содержатся в Соглашениях, принятых по другим отраслям международного права. В частности, в Конвенции ООН по морскому праву 1982 года, Договоре по космосу 1967 г., Договоре о Луне 1979 г. и др.

Кроме того, государства заключают двусторонние соглашения по использованию ядерной энергии в различных областях экономической жизни. В стадии разработки находятся международная конвенция по борьбе с актами ядерного терроризма ${ }^{5}$, договор о запрешении производства расщепляющихся материалов ${ }^{6}$ и др.

Таким образом, формирование и кодификация норм международного ядерного права развивается успешными темпами. Для достижения их эффективности требуется добросовестное выполнение государствами положений действуюших соглашений, а также осуществление эффективного контроля как самими государствами, так и международными организациями, в том числе международными органами, специально созданными в соответствии с соглашениями.

Отечественными учеными довольно подробно рассмотрены контрольный механизм Договора о нераспространении ядерного оружия

Являясь величайшим международным документом современности, Договор доказал свою жизнеспособность в деле нераспространения 
ядерными державами ядерного оружия и других ядерных взрывчатых устройств. Он установил обязательство для неядерных государств не приобретать и не создавать такого оружия или таких устройств. В связи с истечением 25 летнего срока Договор в 1995 году был продлен на бессрочное время. В настояшее время 178 государств являются его участниками, что свидетельствует о его универсальном характере. Систему международного контроля за его выполнением осушествляет МАГАТЭ. Сам механизм контроля заложен как в Договоре о нераспространении, так и в Уставе МАГАТЭ. Более того, МАГАТЭ, как гарант за соблюдением Договора его участниками, заключило соглашение с Европейским Сообшеством по атомной энергии и с неядерными странами. Агентство осуществляет полный контроль за всей ядерной деятельностью его участников, не обладающих ядерных оружием. В своей деятельности МАГАТЭ поддерживает тесные связи практически со всеми государствами мира и многими международными организациями, в том числе с ООН и с ее специализированными учреждениями. Как заметил В. Н. Мишарин, контроль МАГАТЭ в области нераспространения ядерного оружия - сложный материально-технический процесс, который охватывает важнейшие стадии производства и мирного использования атомной энергии

Ежегодно Агентство представляет услуги сотен технических экспертов, которые обучают, консультируют, проводят исследования с целью оказания государствам-членам помощи в развитии самостоятельных программ в области ядерной науки. Значительная часть деятельности Агентства посвяшена развитию ядерной энергетики, включая вопросы ее безопасности и обращения с отходами, и проверке того, что ядерная технология используется исключительно для мирных целей.

Играя ведушую роль в деле предотвращения дальнейшего распространения ядерного оружия, Агентство проводит инспекции более чем 1000 установок во всем мире, привлекая свыше 200 инспекторов.

Международно-правовой режим нераспространения ядерного оружия, созданный главным образом Договором о нераспространении ядерного оружия, является всеобщей, обязательной нормой современного международного права. Ее обязаны соблюдать все государства мира вне зависимости от их участия или неучастия в данном договоре 9

Ряд соглашений, входяший в источники международного ядерного права, были анализированы автором монографии по вопросам осуществления контроля в системе права международной безопасности ${ }^{10}$.

Из принятых в последние годы международных соглашений в международном ядерном праве особое внимание привлекает Договор о всеобъемлющем запрещении ядерных испытаний. Генеральная Ассамблея ООН в резолюции 48/70 от 16 декабря 1993 года призвала все государства поддержать многосторонние переговоры по договору о всеобъемлющем запрещении ядерных испытаний. Данная резолюция, которая была принята единогласно, обеспечила Конференции ООН по разоружению сильную политическую поддержку в самом начале переговоров по договору. При подготовке проекта договора перед участниками Конференции стоял вопрос огромной важности - разработка многостороннего и эффективного механизма международного контроля 
для реализации его положений. Принятие договора, как подчеркнул Генеральный секретарь ООН, оказало бы значительное влияние на нераспространение ядерного оружия, на процесс ядерного разоружения и, следовательно, на укрепление международного мира и безопасности ${ }^{11}$.

В последующие годы работа Конференции по разоружению в Женеве по подготовке Договора о всеобъемлющем запрещении ядерных испытаний успешно продолжалась и в 1996 году Договор был предъявлен на рассмотрение Генеральной Ассамблеи ООН. 10 сентября 1996 года Генеральная Ассамблея ООН приняла Договор о всеобъемлющем запрещении ядерных испытаний. Принятие данного Договора явилось венцом согласованных усилий, предпринимавшихся международным сообществом в течение более четверти века. Он дополняет и расширяет свод норм международного права в области разоружения и контроля над вооружениями. Он имеет огромное символическое значение для конкретного подтверждения приверженности государств, как обладающих, так и не обладаюших ядерным оружием, делу достижения конечной цели, заключающейся в построении мира, полностью свободного от ядерного оружия. Договор установил всеобъемлющие и жесткие положения контроля, которые будут способствовать значительному повышению уровня международного сотрудничества в ядерной области.

Обрашаясь к государствам, обладающим ядерным оружием, несущим главную ответственность за достижение поставленных в Договоре целей, Генеральный секретарь ООН призвал их добросовестно вести между собой и на международных форумах дальнейшие переговоры, направленные на углубление их приверженности делу построения мира, свободного от ядерного оружия, путем сокращения их ядерных арсеналов и ослабления роли последних в деле обеспечения безопасности ${ }^{12}$.

Как ранее было отмечено, Генеральная Ассамблея ООН на заключительном заседании своей 50-й сессии одобрила проект Договора о всеобъемлющем запрешении ядерных испытаний и обратилась к Генеральному Секретарю ООН с просьбой в качестве депозитария договора открыть его для подписания. В преамбуле отмечается, заключение универсального и поддающегося международному и эффективному контролю договора о всеобъемлющем запрещении ядерных испытаний издавна является одной из приоритетных целей международного сообщества в области разоружения и нераспространения ядерного оружия.

В соответствии с Договором каждое государство-участник обязуется не производить любой испытательный взрыв ядерного оружия и любой другой ядерный взрыв, а также запретить и предотвращать любой такой ядерный взрыв в любом месте, находящиеся под его юрисдикцией или контролем. Каждое государство-участник обязуется далее воздерживаться от побуждения, поощрения или какого-либо участия в проведении любого испытательного взрыва ядерного оружия и любого другого ядерного взрыва (ст. 1).

В отличие от Договора 1963 года, запретившего испытания ядерного оружия в атмосфере, в космическом пространстве и под водой независимо от распространения юрисдикции государства-участника, Договор 1996 года обязывает государство-участника вообще не производить 
любых других ядерных взрывов в любой части Земного шара и, более тоro, запретить и предотврашать любые такие взрывы другим государствам и иным лицам в любом месте, находящиеся под его юрисдикцией или контролем.

Кроме того, речь в Договоре идет не только о запрешении испытания ядерного оружия, но и любого другого ядерного взрыва.

По Договору для достижения его объекта или цели, обеспечения осуществления его положений государствами-участниками, включая вопросы контроля за его соблюдением, предусмотрено учреждение Организации по всеобъемлюшему запрешению ядерных испытаний. Членами Организации являются все государства-участники Договора. Для выполнения поставленных перед нею задач создаются соответствующие органы, такие как Конференция государств-участников, Исполнительный совет, Технический секретариат с Международным центром данных. При выполнении своих функций государства-участники сотрудничают с Организацией, проводят консультации непосредственно между собой или через Организацию, либо используя механизмы Устава ООН.

При осуществлении контроля Организация запрашивает только ту информацию и те данные, которые необходимы для выполнения ее обязанностей. При этом должны быть предприняты все меры предосторожности для защиты конфиденциальности информации о гражданской и военной деятельности на объектах проверки.

Государства-участники при использовании такой информации, полученной на доверительной основе от Организации, устанавливают особый режим обращения. Организация, в случае необходимости специальных знаний, вправе вступить в сотрудничество с другими международными организациями, включая МАГАТЭ.

Конференция в соответствии с положениями договора включает от каждого государства-участника одного представителя, которого могут сопровождать заместители и советники.

Eе работа организуется путем созыва ежегодных и специальных сессий. наиболее важные вопросы принимаются путем консенсуса и, если это не удается в соответствии с процедурой Конференции, то большинством в две трети присутствуюших и участвующих в голосовании членов.

Являясь главным органом Организации, Конференция наделяется правом рассматривать любой вопрос в рамках Договора и принимать рекомендации, а также решения по обеспечению реализации положений Договора, его объекта и цели.

Исполнительный Совет, избираемый Конференцией с учетом справедливого географического распределения, состоит из 51 члена. В его обязанности, как исполнительного органа Организации, входит обеспечение и осуществление рекомендаций, решений, руководящих принципов Конференции. Совет содействует эффективному осуществлению и соблюдению Договора, надзирает за деятельностью Технического секретариата, представляет Конференции рекомендации относительно реализации объекта и цели Договора, сотрудничает с Национальным органом каждого государства-участника, заключает с одобрения Кон- 
ференции и от имени Организации соглашения с государствами и международными организациями, выполняет и многие другие функции, предусмотренные в статьях 38-41 Договора.

Одним из органов, непосредственно осуществляющим контроль за соблюдением государствами-участниками положений Договора, является Технический секретариат во главе с Генеральным директором, назначаемым Конференцией по рекомендации Исполнительного совета сроком на 4 года.

Технический секретариат, в состав которого входит в качестве неотьемлемой его части Международный центр данных, выполняет контрольные функции, в которые среди прочего входят: контроль за эксплуатацией Международной системы мониторинга; получение, обработка, анализ данных Международной системы мониторинга; оказание помощи Исполнительному совету, оказание содействия в приготовлении к проведению инспекции на месте, в том числе технической поддержки в ходе их проведения; разработка и заключение с государствами соглашений по вопросу контроля за осуществлением договора и другие.

Договор предусматривает наделение Организации, делегатов государств-членов, членов Исполнительного совета, их заместителей и советников, Генерального директора, инспекторов такими привилегиями и иммунитетами, какие необходимы для независимого осуществления ими своих функций.

Для выполнения своих обязательств по Договору каждое государство-участник назначает или учреждает Национальный орган и информирует об этом Организацию. Каждое государство-участник обязуется принимать меры, запрещающие физическим и юридическим лицам заниматься любой деятельностью, запрещенной государству-участнику по Договору.

В соответствии с положениями Договора режим контроля включает:

- международную систему мониторинга;

- консультации и разъяснения;

- инспекции на месте;

- меры укрепления доверия.

Важнейшим положением Договора являются закрепленные в нем принципы, относяшиеся к деятельности по контролю:

- представление государствами-участниками объективной информации;

- осуществление контроля на основе полного уважения суверенитета государств и как можно менее проникающим образом во внутренние дела государств;

- ограничение пределов контроля предметом Договора;

- воздерживание от любого злоупотребления правом на контроль;

- равенство государств-участников на проведение контроля независимо от их технических и финансовых возможностей;

- зашита каждым государством-участником конфиденциальности любой информации, имеющей отношение $\mathrm{K}$ гражданской и военной деятельности и объектам, которая была получена в ходе контрольной деятельности.

Осуществление Договора не должно создавать помехи экономичес- 
кому и техническому прогрессу государств-участников для дальнейшего развития применения ядерной энергии в мирных целях.

Договор подробно рассматривает методы осуществления контроля.

Так, в ст. VI освещается международная система мониторинга, которая включает объекты сейсмологического, радионуклидного, гидроакустического, инфразвукового мониторинга, соответствующие средства связи. Все объекты по мониторингу в рамках Международной системы мониторинга находятся в собственности государства, эксплуатируются ими, но под началом Технического секретариата Организации. Полученные в результате мониторинга данные хранятся и обрабатываются в Международном центре данных, и имеющая отношение к контролю информация распространяется Техническим секретариатом всем государствам-участникам, предоставляя им равный, открытый, удобный и своевременный доступ ко всем хранимым данным. Государства-участники могут самостоятельно на основе сотрудничества с Организацией предоставлять в распоряжение Международного центра данных дополнительные данные от национальных станций мониторинга, которые не входят официально в состав Международной системы мониторинга.

Каждое государство-участник имеет право запрашивать инспекцию на месте, на территории или в любом другом месте, находящимся под юрисдикцией или контролем любого государства-участника, или в любом районе, находяшемся вне юрисдикции или контроля любого государства. В то же время положения Договора предусматривают необходимость проведения консультаций и разъяснений относительно возможного несоблюдения договорных обязательств, прежде чем сделать запрос на проведение инспекции (ст. IV, П. С). В документе довольно подробно рассматривается механизм инспектирования. Инспекционная группа назначается Генеральным директором Технического секретариата. Каждое государство-участник разрешает Организации провести инспекцию на месте на его территории или в местах, находяшихся под его юрисдикцией или контролем в соответствии с положениями Договора и Протокола с соблюдением ранее названных принципов контроля. Инспектируемое государство оказывает содействие инспекционной группе на протяжении всей инспекции на месте и способствует выполнению ею своей задачи.

При проведении инспекции на месте с согласия инспектируемого государства может участвовать наблюдатель, который является гражданином либо запрашивающего инспекцию государства-участника, либо третьего государства-участника.

Доклад об инспекции на месте представляется Генеральным директором инспектируемому государству, которое имеет право делать свои замечания и пояснения, затем незамедлительно передается запрашивающему государству-участнику, Исполнительному совету и всем другим участникам Договора. Исполнительный совет, рассмотрев доклад, определяет соблюдение положений Договора, не было ли допущено злоупотребление правом запроса относительно проведения инспекции. В случае выявления напуманности и недобросовестности запроса на проведение инспекции, к запрашиваемому государству передается требова- 
ние об оплате расходов по инспекции, а также могут быть принят иные меры, предусмотренные в Договоре.

При установлении по итогам инспекции несоблюдения положений Договора, Конференция или Исполнительный совет предлагает государству-участнику исправить ситуацию, а в случае невыполнения в указанный срок, Конференция может ограничить или приостановить осуществление данным государством-участником его прав и привилегий по Договору.

В случае, когда в результате несоблюдения основных обязательств по Договору может быть причинен ущерб его объекту и цели, Конференция может рекомендовать государствам-участникам коллективные меры, соответствующие международному праву.

$\mathrm{C}$ целью скорейшего урегулирования спора путем переговоров или другими мирным средствами по выбору участников, включая обращение в Международный Суд ООН, государства-участники проводят совместные консультации. Более того, Конференция и Исполнительный совет с разрешения Генеральной Ассамблеи ООН самостоятельно наделены правом обращаться с запросом в Международный Суд о даче консультативного заключения по любому юридическому вопросу, возникающему в рамках сферы деятельности Организации. Эти вопросы регулируются специальными соглашениями между ООН и Организацией ${ }^{13}$.

В протоколе к Договору подробно рассматриваются международная система мониторинга и функции Международного Центра данных, Инспекции на месте, вопросы о назначении инспекторов, их помощников, виды и методы инспекционной деятельности, послеинспекционные процедуры.

Вступление в силу Договора о всеобъемлющем запрешении испытаний ядерного оружия явится важным событием для мирового сообщества накануне XXI века в деле сохранения международной ядерной безопасности и контроля над ядерным оружием и, с другой стороны, прогрессивного развития кодификации норм международного ядерного права.

1 См.: Курс международного права в семи томах. М., 1992, том 5, с. 228.

2 Такого названия, в частности, придерживается В. П. Пархитько, посвятивший свои исследования данной проблеме. См.: Пархитько В. П. Международное ядерное право. М., 1972.

${ }^{3}$ См.: Международное ядерное право. М., 1987, с. 19-20.

4 См.: Договор ООН. А/53/100 от 15 июня 1998 года.

${ }^{5}$ См.: Кофи А. Аннан. Партнерство во имя всемирного сообщества. Годовой доклад о работе ООН за 1998 r. Нью-Йорк, 1998, с. 67.

${ }^{6}$ См.: Бутрос Бутрос Гали. Навстречу новым вызовам. Годовой доклад о деятельности ООН за 1995 г. Нью-Йорк. 1995, с. 467.

${ }^{7}$ Подробнее см.: Тимербаев $P . M$. Мирный атом на международной арене. М., 1969; Международное атомное право, М., 1987, с. 43-709; Малинан С. А. Мирное использование атомной энергии. М., 1971, с. 53-112; Ocunов $\Gamma$. A. Международно-правовой режим нераспространение ядерного оружия. М., 1987, с. 46-89; Мишарин В. Н. Мирное использование атомной энергии. М., 1986, с. 122-150; 
Пархитько В. П. Международное ядерное право. М., 1972, с. 28-33; Нойрыш А.И. Правовые проблемы использования атомной энергии. М., 1979, с. 4-32.

${ }^{8}$ См.: Мишарин B. Н. Указ. соч., с. 122-149.

9 Подробнее см.: Осипов Г. А. Указ. соч., с. 89-93.

${ }^{10}$ Подробнее см.: Валеев Р. M. Международный контроль. Казань, 1998.

${ }^{11}$ См.: Бутрос Бутрос Гали. Во имя мира и развития. ООН. Нью-Йорк, 1994.

${ }^{12}$ CM.: Boutros Boutros Ghali. The $50^{\text {th }}$ Anniversary Annual Report on the work of the Organization. 1996. United Nations, New-York, 1996, p. 311-312/

13 В соответствии со ст. XIV Договор вступает в силу через 180 дней после даты сдачи на хранение ратификационных грамот всеми государствами, перечисленными в Приложении 2, но ни в коем случае не ранее чем через два года, после его открытия для подписания. См.: Действующее международное право. М., 1997, т. 2, с. $338-397$.

Cтатья поступила в редакцию в январе 2000 2.

\title{
МИРНЫЕ ЯДЕРНЫЕ СТАНЦИИ КАК ФАКТОР ВОЕННОГО СДЕРЖИВАНИЯ
}

\author{
Ю.И. К о р я к и н ${ }^{*}$
}

В начале 80-х годов одним из канадских издательств была выпушена монография Б. Рэмберга "Разрушение энергетических установок во время войны”. Книга - итог анализа проведенного в центрах международных и стратегических исследований Принстонского и Калифорнийского университетов США. Книга содержит большой исторический материал, связанный с мотивациями и целями ведения войн, способами достижения военных целей и их эволюцией в зависимости от появления новых средств нападения и ведения войны, а также появления новых техногенных объектов у возможного противника и различных последствий их разрушения или вывода из строя. Такими объектами являются электростанции всех типов. Среди них только ядерная электростанция (ЯЭС) как военная цель для нападающей стороны обладает сильным дополнительным свойством: разрушение ЯЭС сопровождается выбросом радиоактивности, что является дополнительным средством подавления противника. Серьезное внимание к книге было вызвано не только этим, но и приведенными в книге географическими картами. Они показывали катастрофический масштаб радиологических последствий вызванных массовым выбросом радиоактивности в случае отнесения НАТО к первоочередным целям во время войны электростанций противника, в том числе в СССР.

$\mathrm{K}$ тому время в СССР было почти полностью электрифицировано

* Доктор экономических наук, доктор физико-математических наук, действительный член Нью-йоркской академии наук. Подробнее об авторе см. № 2 нашего журнала за 1998 г. 